\title{
Treating Sleep Disorders with an ACT-Based Behavior Change Support System
}

\author{
Sitwat Usman Langrial \\ Sur University College, Dr.Sitwat.Langrial@suc.edu.om \\ Harri Oinas-Kukkonen \\ University of Oulu, harri.oinas-kukkonen@oulu.fi \\ Päivi Lappalainen \\ University of Jyväskylä, paivi.k.lappalainen@jyi.fi \\ Raimo Lappalainen \\ University of Jyväskylä, Raimo.lappalainen@jyi.fi
}

\begin{abstract}
Suitable duration and decent quality of sleep are crucial for mental and cognitive wellbeing. Sleep disorders, whether mild or severe, have proven to have adverse effects on general wellbeing. One's quality of life could be disturbed as a consequence of various mental conditions, sleep disorders being one of them. Researchers have started paying attention to designing, implementing and evaluating eHealth interventions to address sleep disorders. In this chapter, we highlight findings from a field study that was conducted to evaluate effect of software features on a Web-based intervention for sleep disorders. Tyyne is a Web-based eHealth intervention that will be repeatedly mentioned as Behavior Change Support Systsm (BCSS). Tynne offered weekly modules that were drawn from Acceptance and Commitment Therapy (ACT). From an Information System perspective, the modules were identified and applied as a persuasive software feature that is promoted by the Persuasive Systems Design Model (PSD Model). The duration of the Web-based intervention was 6 weeks. Upon completion of the intervention, about one third (37.2\%) of the participants reported that they could better manage their sleep problems. We argue that a relatively low percentage is still highly encouraging, as treatment of sleep-related disorders is a complicated and understudied area. Manifestly, longitudinal studies would help determine the effect of ACT-incorporated Web-based interventions. However, the chapter underscores the effect of persuasive software features incorporated with ACTbased components as a step towards managing sleep disorders.
\end{abstract}

Keywords: Sleep disorders; eHealth, Interventions; Behavior Change Support Systems; Acceptance and Commitment Therapy 


\section{INTRODUCTION}

Suitable duration and decent quality of sleep are crucial for mental and cognitive wellbeing. Sleep disorders, whether mild or severe, have proven adverse effects on general wellbeing. One's quality of life could be poor as a consequence of various mental conditions, sleep disorders being one of them. Sleeplessness both in terms of quality and/or quantity, leads to serious health issues such as cognitive functioning (Frenda \& Fenn, 2016), mood disorder (Kahn-Greene et al. 2007), depression (Hemmeter et al. 2010), obesity (Patel \& Hu, 2008), metabolic disorders and diabetes (Knutson \& Van Cauter, 2008). There could be various reasons for people's unhealthy lifestyles. Because of their detrimental effect on one's mental and general health, sleep disorders are a research area (Langrial et al. 2014; Alhola \& Polo-Kantola, 2007). Literature provides reassuring indications that sleep disorders are negatively correlated with an individual's health and mental wellbeing irrespective of age, gender and social status. According to van Straten and Cuijpers (2009), sleep related disorders, including insomnia, are common among individuals. Sleep deprivation and insomnia have several negative consequences for individuals; for example, fatigue, mood instabilities, psychological stress and addictive disorders (van Straten \&Cuijpers, 2009; Gillin, 1998). Sleep disorders are regularly associated with poor life quality, reduced work productivity, fear, despair, and alcoholism (Walsh, 2004). Further, lack of sleep could adversely affect neurocognitive functioning, as stated earlier. The growing number of the population suffering from sleep disorders is indicative that it has now become a widespread issue (Morin et al 2006). More than $20 \%$ of the adult population alone suffers from sleep disorders (Goel et al. 2009).The effects of sleep disorders on general well-being are frightening(Faubel et al. 2009).

It is a promising sign to note that sleep disorders have received increasing attention because of their negative psychological consequences (Espie et al. 2012; Vincent \& Lewycky, 2009; Ström et al. 2004; Moul et al. 2004). Existing literature has a rich body of studies that focus on healthy diet and regular exercise, and that good sleep quality is vital for health (Choe et al. 2011). EHealth interventions that promote nourishing diet (Purpura et al. 2011) and energetic lifestyles (Albanina et al. 2009) have been well studied. Surprisingly, sleep disorders have gained researchers' attention in more recent times. Mental health conditions, including sleep disorders, pose on-going challenges for researchers from the field of Information Systems, Behavior Change Interventions and Clinical Psychology. Developing and evaluating effective eHealth interventions for sleep disorders calls for creativity leading to novel solutions.

Behavioral Psychology that incorporates Persuasive Software Features has opened up new opportunities to develop novel Cognitive Behavioral Interventions for people with mental health conditions. Promising effects of such interventions have been repeatedly reported, especially when information systems (interventions) are incorporated with Cognitive Behavioral Therapies (Kuonanoja et al. 2015; Andersson \&Cuijpers, 2009; Amstadter et al. 2009; Kiropoulus et al. 2008; Ybarra \& Eaton, 2005).

Several research studies have been conducted in Medicine and Behavioral Psychology. Findings from such studies underline the potential of CBT-based eHealth interventions in better managing sleep-related disorder. For example, Vincent and Lewycky (2009) evaluated the effect of an online intervention for insomnia. The intervention included pyschoeducation and cognitive therapy. Vincent and Lewycky (2009) highlight statistically significant improvements in subjects' sleep quality. Earlier, Ritterband et al. (2009) examined effects of CBT-based intervention for people suffering from 
insomnia. The intervention was based on face-to-face therapy. Ritterband et al. (2009) conclude that the treatment / intervention was effective and people developed positive sleep routines.

A number of factors are known that prevent people with mental disorders from using traditional (face-to-face) treatments. Some of the identified factors include lack of motivation, hesitation to share personal experiences, poor health care facilities, relatively higher treatment costs, privacy concerns and social stigma (Aromaa et al. 2011; Thom \& Campbell, 1997).

There is a recent trend among the Human-Computer Interaction (HCI) researchers relating with studying and investigating eHealth technologies aimed at behavior change (Consolvo et al. 2009). In order to overcome the above-mentioned barriers, several information systems (interventions) have been designed. Researchers have identified promising outcomes from several studies where online cognitive therapies are delivered using persuasive design software (Kuonanoja et al. 2015). Among the studied domains, are, to name a few, smoking cessation, obesity, diabetes, anxiety, stress and depression (e.g. Hamari et al. 2014). Persuasive Information Systems are interactive technologies that are developed with a special focus on helping people change their attitudes and/or behaviors (Fogg, 2002). Another requisite for persuasive information systems is that they do not employ coercion or deception as proposed by (Oinas-Kukkonen \& Harjumaa, 2009).

Realizing the growing and persistent challenge of sleep disorders among general population, presented intervention was designed and examined using a Web-based Behavior Change Support System (Oinas-Kukkonen, 2010, 2013). A Behavior Change Support System can be considered as an extension of Persuasive Information Systems (Langrial, 2012). The main objective of the intervention was to examine and identify likely impact of reminders on task adherence and Acceptance and Commitment-based online rehearsal on the ability to manage sleep behaviors respectively. Online or more specifically, virtual rehearsal is advocated as a persuasive software feature that can help people practice and consequently learn new behaviors (Langrial et al. 2014). As stated earlier, very little research has been conducted on virtual rehearsal (Kelders et al. 2012), especially in the research fields of HCI and eHealth for mental wellbeing.

Psychologists have been emphasizing on the need for developing effective solutions for mental conditions such as sleep disorders. Lim and Dinges (2008) have been persistent in arguing that there is an urgent need to help people manage sleep disorders. Unexpectedly, a limited amount of published literature is available that examines probable explanations and solutions for sleep disorders. For example, Manber et al. (2008) conducted a study to examine the impact of Cognitive Behavioral Therapy on sleeplessness. They suggest that symptom-focused cognitive Behavioral Therapy has promising effects for people suffering for sleeplessness, as well as depression. Langrial et al. (2012) worked on a BCSS for sleep deprivation. They carried out a pilot study and evaluated a web-based BCSS using software features from the Persuasive Systems Design model (Oinas-Kukkonen \&Harjumaa, 2009). The pilot study was conducted to identify whether virtual rehearsal could be used to help people learn new behaviors related with sleep deprivation.

This chapter presents outcomes of a six-week field study. A Web-based eHealth intervention (BCSS) was designed and implemented to support participants learning and practicing new skills to better manage sleep problems. The chapter is structured to 
report participants' pre- intervention expectations, post- intervention remarks and finally identified differences in pre- and post- intervention psychological measures.

\section{BACKGROUND}

Oh et al. (2005) define eHealth as delivering of healthcare solutions using technological platforms such as information systems. The potential advantages of eHealth interventions have been highlighted in terms of reach, ease of access, accessibility, cost effectiveness, and novel sustainable solutions (Murray, 2012). Ritterband and Tate (200) further endorse eHealth interventions for healthcare by highlighting Web-based healthcare interventions as scalable and efficient. It does not come as a surprise that Health Psychology-related research has been utilizing the Internet as a delivery medium frequently (Kraft \&Yardley, 2009).

Current studies reveal success of CBT-based eHealth interventions delivered through the Internet (Andersson and Cuijpers, 2009). Seligman et al. (2011) support the effectiveness of CBT-based eHealth interventions for mental health by proposing that such interventions have indicated noteworthy medical and statistical results. Similarly, Sivertsen et al. (2006) have performed studies on sleeplessness. They propose that CBT-based eHealth interventions are superior when compared with Zoplicone treatment. Cognitive Behavior literature offers adequate support pertaining to the use of CBT-based eHealth interventions.

Yet few studies have reported the use of acceptance and value-based eHealth interventions that employ (Lappalainen et al. 2015) Acceptance and Commitment Therapy (ACT) (e.g. Gaudiano and Herbert, 2006; Forman et al. 2007). ACT is known to increase psychological flexibility because it is positively correlated with improved mental health (Lappalainen et al. 2015; Hayes et al. 2005). Thoughtful works have been performed to develop and assess eHealth for mental well-being with a specific focus on task adherence (Makai et al. 2014), user satisfaction (Kim \& Chang, 2007) and overall psychological outcomes. Adequate sleep is positively correlated with improved health; however, issues related with sleep disorders remain an understudied area. Although reasonable research has been conducted to address the issue in Medical Informatics and Clinical Psychology, still there is manifest lack of investigation about sleep disorders in the fields of Information Systems (Langrial et al. 2012).

It is an encouraging observation that people have shown keen interest and willingness to try out different forms of treatments before deciding to contact healthcare professionals (Morin et al. 2005). Such observations underline noteworthy premises and open opportunities for researchers to overcome identified research gaps. More importantly, it is proposed that people with sleep disorders do not necessarily seek medical treatments. They are eager to try alternative options (Langrial et al. 2012).

HCI researchers have stressed on designing eHealth interventions that can bring envisioned change in users' behaviors. Identifying the scope for treating sleep disorders through Information technology, Choe et al. (2011) propose that technological innovations could be used to improve poor sleep habits. They further argue that designing eHealth interventions for sleep disorders is a challenging task and therefore it is essential to have a thorough understanding of factors including culture, privacy and individual sleep habits. Their work highpoints the importance of improving sleep 
disorders through eHealth interventions, and at the same time indicates that there are design prospects for developing such interventions. While Choe et al. (2011) offer an appealing framework for developing eHealth interventions for sleep disorders, we suggest that their framework does not provide explicit guidelines. Consolvo et al. (2009) emphasize on utilizing behavior change theories when designing eHealth interventions. Their design strategies are valuable; however, to the best of our knowledge, evaluating the effect of definite persuasive software features has been fairly disregarded. This particular gap is evident when it comes to persuasive software features such as virtual rehearsal. Rehearsal or learning through practice (Thorpe et al. 1987) has largely been expended in CBT-related studies. Psychological specialists have recognized intellectual improvements through performance-based process. Importance of rehearsal as a behavior change method has further been testified by (Thorpe et al. 1987) who uphold that rehearsal is a beneficial method for refining self-efficacy.

There is some evidence that supports practicality of rehearsal for learning new behaviors. Jaafar and Nur (2009) studied virtual rehearsal for educating children with an aim to ease dental anxiety. However, the implemented software was more related with simulation, which is different from virtual rehearsal (Oinas-Kukkonen \&Harjumaa, 2009). Similarly, Fogg (2002) promotes virtual rehearsal as a means to provide a setting where people can exercise and learn new behaviors. Rehearsal has also been studied in other settings, for example computer training (Davis \&Yi, 2004). They highlight Social Cognitive Theory (SCT) by Bandura (1986). SCT proposes that learning process is primarily "an information processing activity in which information about the structure of behavior and about environmental events is transformed into symbolic representations that serve as cognitive guides for the construction of complex modes of behavior" (Bandura, 1986, p.51). Niemi et al. (2003) have worked on Webbased learning environments. They grounded their work on Self-regulation, Selfdetermination and Self-efficacy as core psychological procedures that in their opinion can lead to empowering users (Fetterman, 2001). Niemi et al. (2003) state that for learning new skills, rehearsal, critical thinking, and connecting previous and new information are the keys. In their work, Nakanishi et al. (2005) suggest that virtual training simplifies learning process. They conclude that it is comparatively hard to learn new behaviors through reading and simulation, thus supporting the potential of virtual rehearsal as an appropriate method.

We opted to examine selected persuasive software features and their probable effect on the efficiency of a Web-based eHealth intervention (BCSS) for sleep disorder. As stated by Oinas-Kukkonen and Harjumaa (2009), interactive Information Systems are expected to provide immediate feedback and simplify task completion. In other words, we categorize Web-based eHealth interventions as BCSSs that are persuasive in nature, integrated with persuasive software features including, but not limited to, reminders and virtual rehearsal. According to Oinas-Kukkonen (2012), a BCSS is defined as "an information system designed to form, alter or reinforce attitudes, behaviors or an act of complying without using deception, coercion or inducements". Building on Fogg's (2002) seminal work, Oinas-Kukkonen and Harjumaa (2009) proposed a theoretical framework otherwise known as the Persuasive Systems Design model. The model is about methodically designing and evaluating persuasive information systems, in this case the eHealth intervention. Usually, a persuasive system would remind users to perform target behaviors when they are engaged in the interaction. Reminders can improve eHealth interventions (BCSSs) to facilitate task completion (Oinas-Kukkonen 
\&Harjumaa, 2009). Reminders can be of varying designs; for instance, they could be combined as subtle messages (Fry \&Neff, 2009) and can be delivered through different media with varying frequencies. Reminders have regularly been used in persuasive systems for improving general and mental health. Different techniques have been examined to advance the efficiency of reminders with, for example, personalized content. One of the persistent challenges for eHealth interventions is low adherence (task completion/compliance) and learning new skills to manage mental health (Mohr et al. 2010). For the presented study, we formulated the following research questions:

RQ1. How do participants perceive persuasive reminders to help them complete virtual rehearsal tasks?

RQ2. How do participants perceive usefulness of virtual rehearsal in helping them overcome sleep difficulties?

\section{METHODOLOGGY}

\subsection{Recruitment}

The study was conducted between October 2013 and November 2013. Participants were recruited through newspaper advertisements. It was explained in the advertisements that we were looking for those individuals who felt that they were suffering from sleep disorders. The eligibility criteria were: 1) Access to Internet/email, 2) that participants would not take lengthy breaks during the intervention, 3) access to telephone, 4) not being a part of a therapy or study in parallel, 5) Finnish as mother language and 6 ) age 18 years or older.

In response to the advertisements, a total of 122 individuals ( 76 via email and 46 via phone) contacted the university clinic and were screened over phone on the $7^{\text {th }}$ and $8^{\text {th }}$ of October 2013. In addition, those who contacted the university clinic through email were screened on the $17^{\text {th }}$ and $19^{\text {th }}$ of October, 2013. Of the 122 individuals who were initially selected for the study, 14 were excluded because they did not fulfil the eligibility criteria. Further, 22 participants were not included in the study because the number of interested participants was too high and we had rather limited resources to carry out the study in a professional manner. Therefore, the final number of participants was $86(\mathrm{~N}=86)$. Later, measurement packages explaining the objective of the study and informed consent forms were sent out to eligible participants. As the study included actual patients of sleep disorder, ethical approval was formally obtained from the Ethical Committee at the University of Jyväskylä, Finland.

\subsection{Participants' Randomization}

Randomization was performed using the tool (https://www.random.org/lists/) on the 9th of October 2013. Participants were randomized into two groups: (1) Intervention group $(n=43)$ that received the measurements, had access to the intervention (BCSS), received bi-weekly email-based reminders and had access to weekly rehearsal modules, and (2) Wait-list control group $(n=43)$. For ethical reasons, the wait-list control group received the same program (but reminders were not sent) and URL as an access point to the Web-based intervention (BCSS) was sent out when the intervention group had completed the program. The study commenced on the $21^{\text {st }}$ of October and concluded on the $25^{\text {th }}$ of November 2013. This chapter presents results from the intervention group 
only. A total of $12(27.9 \%)$ males and $31(72.1 \%)$ females aged between 24 to 73 years comprised the sample (Mean $=55.74$, Std. Deviation $=10.99)$ A majority of participants $(58.5 \%)$ had obtained higher education either and college or university level.

\subsection{The eHealth Intervention (BCSS Tynne)}

A research group from the Department of Information Processing Science, University of Oulu, Finland devised and implemented the BCSS (Tynne). It was a perplexing task and took several iterations and testing stages before being finalised. A research team from the Department of Psychology, University of Jyväskylä, Finland developed the content for the eHealth intervention (BCSS Tynne), especially the content of ACTbased virtual rehearsal modules. ACT-based rehearsal modules were incorporated with novel techniques for managing sleep disorders. Virtual rehearsal as a software feature was used with an aim to improve mindfulness, acceptance skills, psychological flexibility and commitment towards value-based actions among participants by applying a variety of metaphors, experiential exercises (both audio and video) for mindfulness and Behavioral activation (Hayes et al. 2005). Table 1 presents a brief overview of the ACT themes used for the rehearsal content.

\begin{tabular}{|l|l|l|}
\hline Week & \multicolumn{1}{|c|}{ Theme } & \multicolumn{1}{c|}{ Content } \\
\hline 1 & $\begin{array}{l}\text { Values and value-based } \\
\text { actions }\end{array}$ & $\begin{array}{l}\text { Knowing what matters the most for an individual in } \\
\text { his/her life and acting in accordance }\end{array}$ \\
\hline 2 & The present moment & Living in the present moment (mindfulness) \\
\hline 3 & Cognitive defusion & $\begin{array}{l}\text { Understanding that an individual's thoughts could be } \\
\text { different }\end{array}$ \\
\hline 4 & The observer stance & $\begin{array}{l}\text { Learning to view one's thoughts and feelings from an } \\
\text { observer's stance }\end{array}$ \\
\hline 5 & Acceptance & $\begin{array}{l}\text { Accepting one's feelings, and thoughts and admitting } \\
\text { that one cannot change things }\end{array}$ \\
\hline 6 & Summary & Rehearsing ACT exercises from the previous weeks. \\
\hline Table 1.
\end{tabular}

\subsection{The Persuasive Systems Design Model}

The research field of Persuasive Technology was introduced by Fogg (2002). Generally speaking, persuasive technologies are designed to bring a positive change in people's behaviors. Building upon Fogg's seminal work (Fogg, 2002), Oinas-Kukkonen and Harjumaa (2009) redefined the research area by adding that persuasive systems help people change their behaviors without the use of coercion or deception. Further, use of a persuasive information system has to be on a voluntary basis (Karppinen \& OinasKukkonen, 2013). Oinas-Kukkonen and Harjumaa proposed a theoretical framework else known as the Persuasive Systems Design Model that enables systematic evaluation of the persuasion context (the intent, the event and the persuasion strategy). The model provides a range of persuasive software features and functionalities for developing persuasive eHealth interventions (BCSSs). The four distinct categories outlined in the PSD model are primary task, user-system dialogue, credibility and social support features. Researchers have employed the PSD model in different contexts, for example, Lehto and Oinas-Kukkonen (2011), Räisanen et al. (2010), Stibe et al. (2013), Drozd et al. (2012), Wiafe et al. (2012) and Yetim (2011). The PSD model has also been 
applied in the area of ubiquitous applications that are developed for general well-being (Langrial et al. 2012), personal wearable devices for physical training (Harjumaa et al. 2009), and information systems that promote healthy behavior (Purpura et al. 2011). Kelders et al. (2012) support the use of the PSD model for Web-based interventions. The model does not promote integration of all the proposed software features to develop an effective intervention meaning thereby the persuasiveness of a given eHealth intervention for behavior change is by no means guaranteed in terms of the quantity of incorporated persuasive software features. On the contrary, it is the features of selected software that could lead to an effective intervention or BCSS.

\subsection{Use of virtual rehearsal and reminders.}

The study was planned in a way that the participants were advised to complete and practice one ACT-based virtual rehearsal module before moving on to the next step in the following week. This was intended for two reasons: 1) to provide adequate time for participants to practice and 2) to bring in the element of incremental behavior change process, which is promoted by the PSD model (Oinas-Kukkonen and Harjumaa, 2009). The main objective of sending Email-based reminders was to inspire the participants to interact with the intervention without being obtrusive. Each week three Email-based (automated) reminders were sent out to the participants with an aim to initiate interaction between participants and the intervention (BCSS). The first reminder was to praise the participants for successful completion of the allocated task. For example, the first reminder was sent upon completing rehearsals for week 1 , the second reminder was sent to motivate users to continue practicing skills that they had learned, and the third reminder was sent to advise that participants could access the next rehearsal module and start practicing new skills.

\subsection{Data Collection about participants' experiences.}

System effectiveness and users' overall experience with the intervention (BCSS) were assessed using Likert-scale (Likert, 1932) questionnaires at the beginning and end of the intervention. For data collection, we developed pre- and post- study questionnaires. The questionnaires consisted of two parts. The first part included demographic-related questions formulated to gather information about the participants, their computing skills and experience related with Internet use. The second part in the pre- study questionnaire comprised of questions about participants' anticipations and perceived usefulness of the intervention (BCSS). The post- study questionnaire was developed to gather information about real experiences of the participants after having used the intervention (BCSS). Special emphasis was laid on system usefulness, ease of use; impact of reminders on task completion, effect of virtual rehearsal on sleep management skills, and participants' observations about the efficiency of virtual rehearsal. We used seven-point rating scales for all items $(1=$ Strongly disagree; $7=$ Strongly agree) (Likert, 1932). Finally, participants were interviewed in a post- study satisfaction (exit) survey to get a better picture of their experiences with the intervention.

\subsection{Measures for well-being.}

We used Beck Depressive Inventory-II (BDI-II) (Beck et al. 1961) and Epworth Sleepiness Scale (ESS) (Johns, 1991) for measuring psychological outcomes. Beck 
Depressive Inventory II includes of 21 questions about depressive symptoms and their severity. The scale ranges from $0-63$ (where $0-13$ no or few depressive symptoms, $14-19$ indicate mild depression, $20-28$ indicate moderate depression and $29-63$ indicate severe depression). BDI-II has been acknowledged to have reliability and validity in both among clinical and non-clinical populations. Epworth Sleepiness Scale (ESS) is a self-administrated eight-item questionnaire (Johns, 1992). It establishes the level of sleepiness during daytime (Johns, 1991). An ESS score that is greater than 16 indicates a high level of daytime sleepiness. The ESS has proven to be reliable and internally consistent tool (Johns, 1992).

\section{DATA EVALUATION}

We applied the PSD model to evaluate the effectiveness of the intervention. The model outlines 28 distinct persuasive software features; however for the purpose of this study, only reminders and virtual rehearsal were chosen as key software features. The goal of the study was to examine the effect of reminders on task completion and / or compliance. The major task for the participants was to learn new behaviors through practice for better managing sleep disorders through ACT-based virtual rehearsal modules. Particular emphasis was placed upon the said software features to understand how a combination of the two could be further utilized to develop operative and effective eHealth interventions (BCSSs) for sleep disorders. In addition, we aimed to investigate participants' anticipations from the intervention in terms of system usefulness, ease of use, expected enjoyment, whether participants perceived virtual rehearsal useful software feature, their willingness to use the system, and whether participants considered reminders to be effective. Using structured questionnaires, we opted for collecting qualitative date.

Participants completed pre- and post- study questionnaires representing their replies both in terms of anticipations and real experiences respectively. Finally, participants were given an option to give additional remarks about the intervention. For the purpose of the analyses and to answer aforementioned questions, we followed a qualitative research methodology. We used elements of the Grounded Theory (Strauss and Corbin, 1998). It allows using previously defined themes and, at the same time provides an opportunity to collect emerging themes as stated by Fereday and Muir-Ccochrane (2008). Further, we evaluated frequency distribution between pre- and postmeasurements using Chi-square test.

\section{FINDINGS}

Table 2 exemplify participants' responses for both pre- and post- study questionnaires. The table exhibits pre- and post- intervention responses in percentage (Agreed; Unsure or Disagreed), pre- and post- intervention mean sores and standard deviation (SD), and t-test revealing statistical differences between pre- and post- mean values. 


\begin{tabular}{|c|c|c|c|c|c|}
\hline Question/Theme & $\begin{array}{l}\text { Pre } \\
\% \\
\text { (n) }\end{array}$ & $\begin{array}{l}\text { Post } \\
\% \\
\text { (n) }\end{array}$ & $\begin{array}{l}\chi^{2} \\
3.7 .1 .1\end{array}$ & $\begin{array}{l}\text { Pre: } \\
\text { Mean } \\
\text { (sd) }\end{array}$ & $\begin{array}{l}\text { Post: } \\
\text { Mean } \\
\text { (sd) }\end{array}$ \\
\hline $\begin{array}{l}\text { The } \\
\text { intervention(BCSS) } \\
\text { will improve my sleep } \\
\text { habits/helped me } \\
\text { improve my sleep } \\
\text { habits }\end{array}$ & & & & $\begin{array}{l}2.91 \\
(.29)\end{array}$ & $\begin{array}{l}2.54 \\
(.67)\end{array}$ \\
\hline Agreed & $\begin{array}{l}90.7 \% \\
(39)\end{array}$ & $\begin{array}{c}60.5 \% \\
(26)\end{array}$ & $\begin{aligned} \chi^{2}= & 9.83 ; \mathrm{df} \\
& =2 \\
& p<0.01\end{aligned}$ & & \\
\hline Unsure or Disagreed & $\begin{array}{c}9.3 \% \\
(4) \\
\end{array}$ & $\begin{array}{c}34.9 \% \\
(15) \\
\end{array}$ & & & \\
\hline $\begin{array}{l}\text { The intervention } \\
\text { (BCSS) will be/was } \\
\text { easy to interact with }\end{array}$ & & & & $\begin{array}{l}2.77 \\
(.48)\end{array}$ & $\begin{array}{l}2.95 \\
(.26)\end{array}$ \\
\hline Agreed & $\begin{array}{c}79.1 \% \\
(36)\end{array}$ & $\begin{array}{c}90.7 \% \\
(39)\end{array}$ & $\begin{array}{c}\chi^{2}=2.85 \\
\mathrm{df}=2 \\
\mathrm{p}=0.09\end{array}$ & & \\
\hline Unsure or Disagreed & $\begin{array}{c}20.9 \% \\
(7) \\
\end{array}$ & $\begin{array}{c}4.7 \% \\
(2) \\
\end{array}$ & & & \\
\hline $\begin{array}{l}\text { Web-based } \\
\text { interventions(BCSSs) } \\
\text { for sleep disorders is a } \\
\text { good idea }\end{array}$ & & & & $\begin{array}{l}2.88 \\
(.50)\end{array}$ & $\begin{array}{l}2.83 \\
(.38)\end{array}$ \\
\hline Agreed & $\begin{array}{c}93.0 \% \\
(40)\end{array}$ & $\begin{array}{c}79.1 \% \\
(34)\end{array}$ & $\begin{aligned} \chi^{2}= & 4.22 ; \mathrm{df} \\
& =2 \\
& =0.12\end{aligned}$ & & \\
\hline Unsure or Disagreed & $\begin{array}{l}7.0 \% \\
(3) \\
\end{array}$ & $\begin{array}{c}16.3 \% \\
(7)\end{array}$ & & & \\
\hline $\begin{array}{l}\text { Learning new skills } \\
\text { through Web-based } \\
\text { interventions (BCSSs) } \\
\text { is a good idea }\end{array}$ & & & & $\begin{array}{c}2.93 \\
(.258)\end{array}$ & $\begin{array}{c}2.98 \\
(.156)\end{array}$ \\
\hline Agreed & $\begin{array}{c}93.0 \% \\
(40)\end{array}$ & $\begin{array}{c}93.0 \% \\
(40)\end{array}$ & $\begin{array}{c}\chi^{2}=0.93 \\
d f=1 \\
p=0.33\end{array}$ & & \\
\hline Unsure or Disagreed & $\begin{array}{l}7.0 \% \\
(3) \\
\end{array}$ & $\begin{array}{l}2.3 \% \\
(1) \\
\end{array}$ & & & \\
\hline $\begin{array}{l}\text { Reminders will help } \\
\text { people complete Web- } \\
\text { based interventions }\end{array}$ & & & & $\begin{array}{l}2.95 \\
(.213)\end{array}$ & $\begin{array}{c}2.68 \\
(.610)\end{array}$ \\
\hline Agreed & $\begin{array}{c}95.3 \% \\
(41)\end{array}$ & $\begin{array}{c}72.1 \% \\
(31)\end{array}$ & $\begin{array}{l}\chi^{2}=7.12 \\
\mathrm{df}=2\end{array}$ & & \\
\hline
\end{tabular}




\begin{tabular}{|l|c|c|c|c|c|}
\hline & & $\mathrm{p}=0.03$ & & \\
\hline Unsure or Disagreed & $\begin{array}{c}4.7 \% \\
(2)\end{array}$ & $\begin{array}{c}23.3 \% \\
(10)\end{array}$ & & & \\
\hline $\begin{array}{l}\text { After using the } \\
\text { intervention (BCSS), I } \\
\text { will be/am able to } \\
\text { manage my sleep } \\
\text { problems better }\end{array}$ & $\begin{array}{c}88.4 \% \\
(38)\end{array}$ & $\begin{array}{c}37.2 \% \\
(16)\end{array}$ & $\begin{array}{c}\chi^{2}=22.63 ; \\
\mathrm{df}=2 \\
\mathrm{p}=<0.01\end{array}$ & $\begin{array}{c}(.324) \\
(.610)\end{array}$ & \\
\hline $\begin{array}{l}\text { Agreed } \\
11.6 \%\end{array}$ & $\begin{array}{c}58.2 \% \\
(5)\end{array}$ & \multicolumn{2}{|c|}{$\begin{array}{l} \\
(25)\end{array}$} & & \\
\hline Unsure or Disagreed & \multicolumn{3}{|c|}{ Pre- and post- study responses depicting statistical outcomes. } \\
\hline
\end{tabular}

\subsection{Psychological Measures}

Symptoms of sleeplessness were assessed at the beginning and the end of the study. For measuring psychological symptoms, Beck Depression Inventory-II (BDI-II) (Beck et al. 1961) and Epworth Sleepiness Scale (ESS) (Johns, 1991) were used as primary measures. BDI-II (Beck et al. 1961) was used as a primary measure because depression is a common reason for sleeplessness and other sleep disorders (Hall et al. 2000). ESS (Johns, 1991) provides valid measurements of sleep propensity in adults. Outcomes from the analysis for pre- and post- BDI-II measurements revealed statistically significant decreases in the intervention group where mean values dropped from 12.20 to $8.15(\mathrm{t}=5.54, \mathrm{df}=38, \mathrm{p}<0.01)$. Similarly, promising results were observed when ESS was analysed. Outcomes from the pre- and post- study for ESS showed notable decrease in mean values from 6.98 to 5.63 ( 02.59 , $\mathrm{df}=37, \mathrm{p}<0.05$ ). Mean values for the psychological measurements provide evidence that support overall effectiveness of the intervention. Figure 1 exhibits scores for Mean and Standard Deviation for Intervention group.

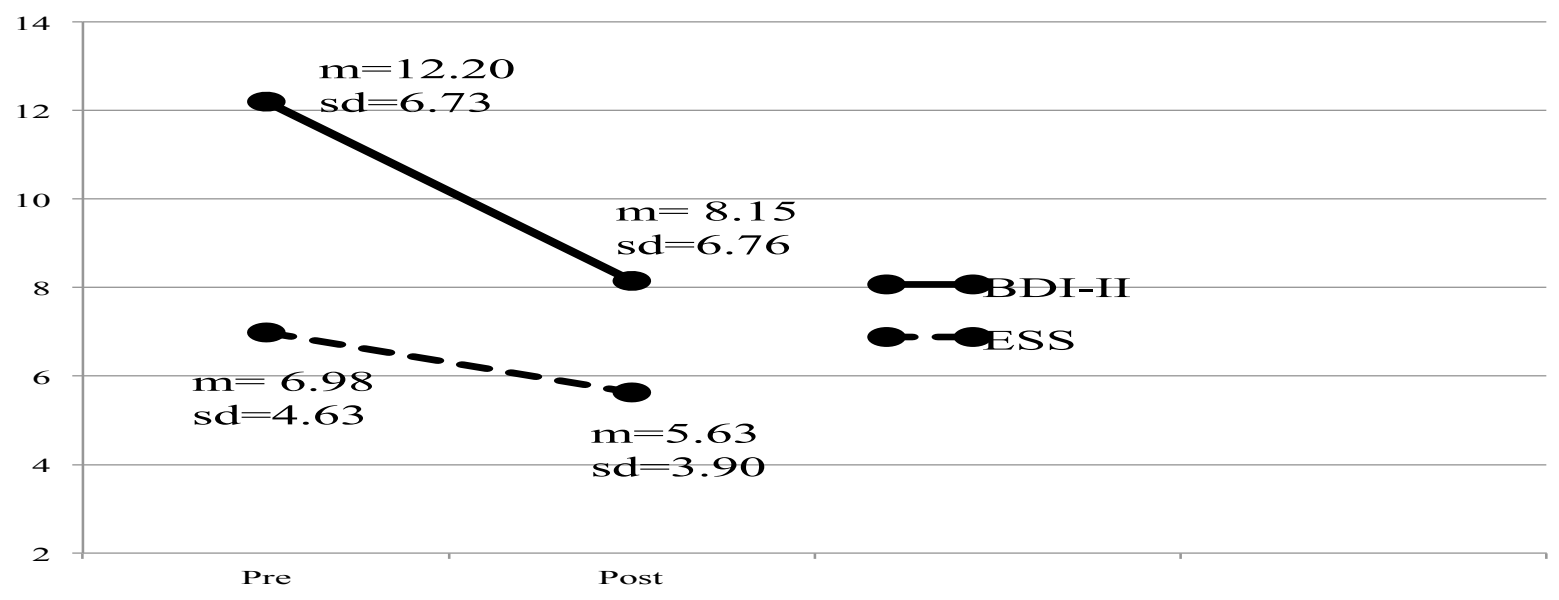

Figure 1. Mean scores and standard deviations for psychological measures. 


\subsection{Participants' open comments}

Of the 43 participants, 41 volunteered to complete post- study questionnaires. Several observations were noticed and themes were identified. Keeping in mind the identified themes, below are some of the exemplary comments:

\subsubsection{Need for extended interaction}

"A little more interaction (prolonged period of study) would have been better (desirable) otherwise it was a good experience”. (Female; 45 years)

"I had high expectations but I did not have enough time for the system (to interact with the system)". (Female; 45 years)

"The program (intervention) did not help me. The study period should have been longer". (Male; 53 years)

"The period of the study (intervention) was too short". (Male; 58 years)

\subsubsection{Reminders are beneficial}

"The system met my expectations. Reminders worked fine. Adding SMS-based reminders would have been better". (Male; 53 years)

"The system was good! I found reminders and rehearsal to be beneficial". (Female; 62 years)

"I expected a little more from the system. The rehearsals were good and so were the reminders (they were much needed)". (Female; 62 years)

\subsubsection{Virtual rehearsal is a suitable method}

"I got to know myself (better) and now I have new (better) viewpoints (about my life)". (Female; 65 years)

"I am highly grateful! I am (feel calm) about my waking up during night time and (now) I (manage) to sleep gain”. (Female; 65 years)

"I had no problems using the intervention (BCSS). It was (indeed) a positive experience. The program (intervention) was well built (designed) both technically and content wise. There was enough information given the short study (intervention) period. My sleep did not improve. The process of improvement was just starting (to happen). I learned new views (techniques) to think about my life". (Female; 67 years) 
."There was a lot of new information. The program provided broad (comprehensive) approaches towards sleep problems, it was engaging. Although, my sleep problems are the same I will continue to rehearse". (Male; 67 years)

The system (BCSS) was easy to use. Rehearsals were reasonable (logical). It was an interesting experience. I (would) highly recommend using the (same) system. Now, I can sleep easily and (also) breathe better". (Female; 50 years)

"I cannot compare this (experience) to anything else. The memories are pleasant. I would like to take part in something similar (intervention) in future". (Female; 63 years)

"The system met my expectations. It was a positive experience. Working out the exercises (rehearsing) has improved my situation". (Female; 57 years)

"The system was good. It did not resolve my insomnia but I still feel it (the BCSS) was useful”. (Female; 47 years)

"Very surprising and exciting experience. I committed (myself) to the program (intervention) and learnt new skills. The best results are thoughtfulness that I have achieved in six weeks". (Female; 56 years)

"The system taught me to listen, breathe and meditate well. It helped me accept that there are bad times. Thank you". (Female; 56 years)

"My expectations were met and exceeded. Quality of sleep has increased remarkably. Length of sleep is bit better. Not so much of awakening during night. Best of all, I have almost quit using sleeping pills." (Female; 50 years)

\subsubsection{General remarks}

"I did not have any expectations (that my sleep problems will be solved)." (Female; 60 years)

"I expected a more from the system (intervention). However, my own laziness (has) influenced my (learning) progress". (Male; 51 years)

"The system met my expectations. I had problems because of my Internet connection. (Female; 64 years)

"I am still practising (rehearsing). Let us see what happens". (Female; 56 years)

"The program (intervention) was positive (good). I just did not have much time. It was worth a try". (Male; 59 years) 


\section{DISCUSSION}

The central objective of the study was to evaluate (1) how do participants perceive reminders support them completing weekly tasks and, (ii) how do they perceive likely effect of virtual rehearsal in overcoming sleep disorder. According to Oinas-Kukkonen and Harjumaa (2009). effective dialogue support features should be integrated to keep the users motivated in continuing to interact with the system / intervention and supporting them to reach their goals. It has been stated that features supporting users' primary task are necessary for persuasion (Oinas-Kukkonen and Harjumaa 2009). Additionally, primary task support features aim to improve users' self-efficacy by reducing rational burden and perplexity (Webster \& Ahuja 2006). This study demonstrates how the PSD model can be utilized in developing and evaluating an eHealth intervention (BCSS).

It is apparent that the participants had high hopes from the intervention; however upon completion of the intervention, the post- study survey responses indicate a relatively different picture. We had two research questions for this study. RQ1 was aimed to examine how and to what extent reminders helped users in task completion/compliance. Post- study results suggest that reminders were perceived as helpful. This is especially evident in participants' open comments, where majority of the participants $(72.1 \%)$ commended reminders as an appropriate technique for task completion/compliance in both pre- and post- study questionnaires. RQ2 was developed to examine the extent to which virtual rehearsal could help participants learn new behaviors. An overwhelming majority of participants (93.1\%) favoured virtual rehearsal as an effective feature for learning new behaviors. In addition, participants' open comments provide evidence that support usefulness of virtual rehearsal. Several participants expressed their desire for an extended period of the intervention.

A prominent limitation of presented work is that the time duration of the intervention was relatively short. Chronic mental conditions such as sleep disorder require a prolonged interaction between users and the intervention (BCSS). However, our work opens new opportunities for e-Health researchers to further investigate selected software features that could improve effectiveness of interventions that are designed for sleep disorders.

\section{CONCLUSION}

This chapter highlights findings from evaluation of a Web-based eHealth intervention (BCSS) for sleep disorders. The software features were drawn from the PSD model, however; the main focus was on examining the effect of reminders and virtual rehearsal. Majority of the participants agreed that the intervention was helpful. Nearly all the participants agreed that learning new skills through Web-based interventions was a good idea. Although most of the participants agreed at the beginning of the intervention that reminders might help them in task completion, the number decreased significantly upon completion of the intervention. A high majority of the participants expected that upon completion of the intervention, they would be able to manage their sleep problems better. However, it was observed that several participants' expectations were not met.

Nevertheless, 16 participants agreed that they could better manage their sleep problems, 22 participants were unsure and 3 participants disagreed upon completion of the 
intervention. One major reason for this outcome is relatively short time period of the intervention. Although the intervention lasted for a period of six weeks only, still the findings are encouraging because the entire intervention was carried without face-toface therapy and a significant number of participants evaluated the intervention positively.

We believe that our work is a good starting point to develop and evaluate novel eHealth interventions that are designed with intent to help people suffering from mental conditions such as sleep disorders. Our work has several implications for eHealth, HCI and IS researchers especially those who wish to analyse the effect of reminders on task completion and virtual rehearsal such interventions.

Acknowledgements. The study was a part of the OASIS research group of Martti Ahisaari Institute, University of Oulu, Finland. The SalWe Research Program supported it for Mind and Body (Tekes - The Finnish Funding Agency for Technology \& Innovation grant 1104/10). The contribution made by the research group at the Department of Psychology, University of Jyväskylä cannot be overlooked. The authors thank the entire team for the effort and contribution in completing the study.

\section{REFERENCES}

Albaina, I. M., Visser, T., van der Mast, C. A., \& Vastenburg, M. H. (2009, April). Flowie: A persuasive virtual coach to motivate elderly individuals to walk. In Pervasive Computing Technologies for Healthcare, 2009. Pervasive Health 2009. 3rd International Conference on (pp. 1-7). IEEE.

Alhola, P., \& Polo-Kantola, P. (2007). Sleep deprivation: Impact on cognitive performance. Neuropsychiatric disease and treatment, 3(5), 553.

Amstadter, A. B., Broman-Fulks, J., Zinzow, H., Ruggiero, K. J., \& Cercone, J. (2009). Internet-based interventions for traumatic stress-related mental health problems: a review and suggestion for future research. Clinical psychology review, 29(5), 410420.

Andersson, G., and Cuijpers, P.: Internet-based and other computerized psychological treatments for adult depression: a Meta-analysis. Cog Behav Ther 2009 Dec; 38 (4): 196-205

Aromaa, E., Tolvanen, A., Tuulari, J., \& Wahlbeck, K. (2011). Personal stigma and use of mental health services among people with depression in a general population in Finland. BMC psychiatry, 11(1), 52.

Bandura, A. (1986). Social foundations of thought and action (pp. 5-107). Prentice Hall.: Englewood Cliffs, NJ.

Beck, A. T., Ward, C., \& Mendelson, M. (1961). Beck depression inventory (BDI). Arch Gen Psychiatry, 4(6), 561-571.

Briñol, P., and Petty, R. E. (2009). Persuasion: Insights from the self-validation hypothesis. Adv. Exp. Soc. Psychol. 41, 69-118.

Choe, E. K., Consolvo, S., Watson, N. F., \& Kientz, J. A. (2011, May). Opportunities for computing technologies to support healthy sleep behaviors. In Proceedings of the SIGCHI Conference on Human Factors in Computing Systems (pp. 3053-3062). ACM.

Consolvo, S., McDonald, D. W., and Landay, J. A. (2009, April). Theory-driven design strategies for technologies that support behavior change in everyday life. In 
Proceedings of the SIGCHI Conference on Human Factors in Computing Systems (pp. 405-414). ACM.

Andersson, G., \& Cuijpers, P. (2009). Internet-based and other computerized psychological treatments for adult depression: a meta-analysis. Cognitive behavior therapy, 38(4), 196-205.

Davis, F. D., \& Yi, M. Y. (2004). Improving Computer Skill Training: Behavior Modeling, Symbolic Mental Rehearsal, and the Role of Knowledge Structures. Journal of Applied Psychology, 89(3), 509.

Dey, A. K. (2001). Understanding and using Context. Pers. Ubiquit. Comput. 5, 1, 4 7.

Drozd, F., Lehto, T., \& Oinas-Kukkonen, H. (2012). Exploring perceived persuasiveness of a behavior change support system: a structural model. In Persuasive Technology. Design for Health and Safety (pp. 157-168). Springer Berlin Heidelberg.

Espie, C. A., Kyle, S. D., Williams, C., Ong, J. C., Douglas, N. J., Hames, P., \& Brown, J. S. (2012). A randomized, placebo-controlled trial of online cognitive behavioral therapy for chronic insomnia disorder delivered via an automated media-rich web application. Sleep, 35(6), 769-781.

Faubel, R., Lopez-Garcia, E., Guallar-Castillón, P., Balboa-Castillo, T., GutiérrezFisac, J. L., Banegas, J. R., \& Rodríguez-Artalejo, F. (2009). Sleep duration and health-related quality of life among older adults: a population-based cohort in Spain. Sleep, 32(8), 1059.

Frenda, S. J., \& Fenn, K. M. (2016). Sleep Less, Think Worse: The Effect of Sleep Deprivation on Working Memory. Journal of Applied Research in Memory and Cognition, 5(4), 463-469.

Fetterman, D. M. (2001). Foundations of empowerment evaluation. Sage.

Fereday, J., \& Muir-Cochrane, E. (2008). Demonstrating rigor using thematic analysis: A hybrid approach of inductive and deductive coding and theme development. International journal of qualitative methods, 5(1), 80-92.

Fogg, B. J. (2002). Persuasive technology: using computers to change what we think and do. Ubiquity, 2002(December), 5.

Fogg, B. J. (2009). A behavior model for persuasive design. In Proceedings of the 4th International Conference on Persuasive Technology (Claremont, CA, USA, April 26 - 29, 2009). Persuasive '09. ACM, New York, NY.

Forman, E. M., Herbert, J. D., Moitra, E., Yeomans, P. D., \& Geller, P. A. (2007). A randomized controlled effectiveness trial of acceptance and commitment therapy and cognitive therapy for anxiety and depression. Behavior Modification, 31(6), 772-799.

Fry, J. P. and Neff, R. A.: Periodic Prompts and Reminders in Health Promotion and Health Behavior Interventions: Systematic Review. In: Journal of Medical Internet Research. 2009 April-June; 11(2): e16

Gaudiano, B. A., \& Herbert, J. D. (2006). Acute treatment of inpatients with psychotic symptoms using Acceptance and Commitment Therapy: Pilot results. Behavior Research and Therapy, 44(3), 415-437.

Gefen, D. and Straub, D., (2000). The relative importance of perceived ease of use in IS adoption: A study of e-commerce adoption. JAIS 1, 1, Article 8. Available at: http://aisel.aisnet.org/jais/vol1/iss1/8 (Last accessed: Oct 29, 2011)

Gillin, J. C. (1998). Are sleep disturbances risk factors for anxiety, depressive and addictive disorders?. Acta Psychiatrica Scandinavica, 98(s393), 39-43. 
Goel, N., Rao, H., Durmer, J. S., \& Dinges, D. F. (2009, September). Neurocognitive consequences of sleep deprivation. In Seminars in neurology (Vol. 29, No. 4, p. 320). NIH Public Access.

Hall, M., Buysse, D. J., Nowell, P. D., Nofzinger, E. A., Houck, P., Reynolds, C. F., \& Kupfer, D. J. (2000). Symptoms of stress and depression as correlates of sleep in primary insomnia. Psychosomatic Medicine, 62(2), 227-230.

Hamari, J., Koivisto, J., \& Pakkanen, T. (2014, May). Do persuasive technologies persuade?-a review of empirical studies. In International Conference on Persuasive Technology (pp. 118-136). Springer International Publishing.

Hassenzahl, M. and Tractinsky, N. (2006). User experience - a research agenda. Behavior \& Information Technology, 25 (2), 91-97.

Hayes, S. C., Luoma, J. B., Bond, F. W., Masuda, A., and Lilles, J.: Acceptance and Commitment Therapy: Model, Processes and Outcomes. Behavioral Research and Therapy 44, 2005, 1-25

Hemmeter, U. M., Hemmeter-Spernal, J., \& Krieg, J. C. (2010). Sleep deprivation in depression. Expert review of neurotherapeutics, 10(7), 1101-1115.

Jaafar, W. A., \& Nur, S. (2009). Applying Virtual Rehearsal Principle in Developing a Persuasive Multimedia Learning Environment (PMLE). In Visual Informatics: Bridging Research and Practice (pp. 427-435). Springer Berlin Heidelberg.

Johns, M. W. (1992). Reliability and factor analysis of the Epworth Sleepiness Scale. Sleep, 15(4), 376-381.

Johns, M. W. (1991). A new method for measuring daytime sleepiness: the Epworth sleepiness scale. Sleep, 14(6), 540-545.

Kahn-Greene, E. T., Killgore, D. B., Kamimori, G. H., Balkin, T. J., \& Killgore, W. D. (2007). The effects of sleep deprivation on symptoms of psychopathology in healthy adults. Sleep medicine, 8(3), 215-221.

Karppinen, P., \& Oinas-Kukkonen, H. (2013, April). Three approaches to ethical considerations in the design of behavior change support systems. In International Conference on Persuasive Technology (pp. 87-98). Springer Berlin Heidelberg.

Kelders, S. M., Kok, R. N., Ossebaard, H. C., \& Van Gemert-Pijnen, J. E. (2012). Persuasive system design does matter: a systematic review of adherence to webbased interventions. Journal of medical Internet research, 14(6).

Kim, D., \& Chang, H. (2007). Key functional characteristics in designing and operating health information websites for user satisfaction: An application of the extended technology acceptance model. International journal of medical informatics, 76(11), 790-800.

Kiropoulos, L. A., Klein, B., Austin, D. W., Gilson, K., Pier, C., Mitchell, J., \& Ciechomski, L. (2008). Is internet-based CBT for panic disorder and agoraphobia as effective as face-to-face CBT?. Journal of anxiety disorders, 22(8), 1273-1284.

Kuonanoja, L., Langrial, S., Lappalainen, R., Lappalainen, P., \& Oinas-Kukkonen, H. (2015). Treating depression with a behavior change support system without face-toface therapy. AIS Transactions on Human-Computer Interaction, 7(3), 192-210.

Knutson, K. L., \& Van Cauter, E. (2008). Associations between sleep loss and increased risk of obesity and diabetes. Annals of the New York Academy of Sciences, 1129(1), 287-304.

Knutson, K. L., Spiegel, K., Penev, P., \& Van Cauter, E. (2007). The metabolic consequences of sleep deprivation. Sleep medicine reviews, 11(3), 163-178.

Kraft, P., \& Yardley, L. (2009). Current issues and new directions in Psychology and Health: What is the future of digital interventions for health behavior change? 
Langrial, S., Oinas-Kukkonen, H., Lappalainen, P., \& Lappalainen, R. (2014). Influence of Persuasive reminders and Virtual Rehearsal on Information Systems for Sleep Deprivation. In PACIS (p. 228).

Langrial, S. (2012). From digital interventions to behavior change support systems: Understanding persuasive systems' development and evaluation process. In Proceedings of IRIS (Vol. 2012, pp. 1-16).

Langrial, S., Oinas-Kukkonen, H., \& Wang, S. (2012). Design of a Web-Based Information System for Sleep Deprivation-A Trial Study. In Exploring the Abyss of Inequalities (pp. 41-51). Springer Berlin Heidelberg.

Lappalainen, P., Langrial, S., Oinas-Kukkonen, H., Tolvanen, A., \& Lappalainen, R. (2015). Web-based acceptance and commitment therapy for depressive symptoms with minimal support: a randomized controlled trial. Behavior modification, 39(6), 805-834.

Lee, E.-J. (2009). I like you, but I won't listen to you: Effects of rationality on affective and Behavioral responses to computers that flatter. Int. J. Hum.-Comput. St. 67, 8, $628-63$.

Lehto, T., \& Oinas-Kukkonen, H. (2011). Persuasive features in web-based alcohol and smoking interventions: a systematic review of the literature. Journal of medical Internet research, 13(3).

Likert, R. (1932). A technique for the measurement of attitudes. Archives of psychology.

Lim, J., \& Dinges, D. F. (2008). Sleep deprivation and vigilant attention. Annals of the New York Academy of Sciences, 1129(1), 305-322.

Lockton, D., Harrison, D., Stanton, N. (2008). Design with intent: Persuasive technology in a wider context. In Proceedings of the 3rd International Conference on Persuasive Technology (Oulu, Finland, June 4-6, 2008). Persuasive '08. Springer-Verlag, Berlin, Heidelberg. Lecture Notes in Computer Science, vol. 5033, 274-278.

Manber, R., Edinger, J. D., Gress, J. L., San Pedro-Salcedo, M. G., Kuo, T. F., \& Kalista, T. (2008). Cognitive behavioral therapy for insomnia enhances depression outcome in patients with comorbid major depressive disorder and insomnia. sleep, $31(4), 489$.

Makai, P., Perry, M., Robben, S. H., Schers, H. J., Heinen, M. M., Rikkert, M. G. O., \& Melis, R. F. (2014). Evaluation of an eHealth intervention in chronic care for frail older people: why adherence is the first target. Journal of medical Internet research, 16(6), e156.

Mohr, D. C., Duffecy, J., Jin, L., Ludman, E. J., Lewis, A., Begale, M., \& McCarthy Jr, M. (2010). Multimodal e-mental health treatment for depression: a feasibility trial. Journal of medical Internet research, 12(5).

Morin, C. M., LeBlanc, M., Daley, M., Gregoire, J. P., \& Merette, C. (2006). Epidemiology of insomnia: prevalence, self-help treatments, consultations, and determinants of help-seeking behaviors. Sleep medicine, 7(2), 123-130.

Morin, C.M., Beaulieu-Bonneau, S., LeBlanc, S., Savard, M.: Self-help Treatment for Insomnia: A Randomized Controlled Trial. Sleep 28 (2005)

Moul, D. E., Hall, M., Pilkonis, P. A., \& Buysse, D. J. (2004). Self-report measures of insomnia in adults: rationales, choices, and needs. Sleep medicine reviews, 8(3), 177198.

Murray, E. (2012). Web-based interventions for behavior change and self-management: potential, pitfalls, and progress. Medicine 2.0, l(2), e3. 
Nakanishi, H., Shimizu, S., \& Isbister, K. (2005). Sensitizing social agents for virtual training. Applied Artificial Intelligence, 19(3-4), 341-361.

Niemi, H., Nevgi, A., \& Virtanen, P. I. (2003). Towards self-regulation in web-based learning. Journal of Educational Media, 28(1), 49-71.

Oinas-Kukkonen Harri (2013) A foundation for the study of behavior change support systems. Personal and ubiquitous computing, Vol. 17, No. 6, August 2013, pp. 1223-1235.

Oinas-Kukkonen, H. (2010). Behavior change support systems: A research model and agenda. In Proceedings of the 5th International Conference on Persuasive Technology (Copenhagen, Denmark, June 7-10, 2010). Springer-Verlag, Berlin, Heidelberg, Lecture Notes in Computer Science, Vol. 6137, 4-14.

Oinas-Kukkonen, H. and Harjumaa, M. (2009). Persuasive systems design: Key issues, process model, and system features. Comm. Assoc. Inform. Sys. 24, 1, Article 28. Available at: http://aisel.aisnet.org/cais/vol24/iss1/28

Oinas-Kukkonen, H. and Harjumaa, M. (2008). A Systematic Framework for Designing and Evaluating Persuasive Systems. In Proceedings of the 3rd International Conference on Persuasive Technology (Oulu, Finland, June 4-6, 2008). Persuasive '08. Springer-Verlag, Berlin, Heidelberg. Lecture Notes in Computer Science, vol. 5033, pp. 164-176.

Patel, S. R., \& Hu, F. B. (2008). Sleep deprivation and obesity. Obesity epidemiology, 320.

Portnoy, D. B., Scott-Sheldon, L. A. J., Johnson, B. T., and Carey M. P. (2010). Computer delivered interventions for health promotion and Behavioralrisk reduction: A meta-analysis of 75 randomized controlled trials. Prev. Med. 47, 3-16.

Purpura, S., Schwanda, V., Williams, K., Stubler, W., \& Sengers, P. (2011, May). Fit4life: the design of a persuasive technology promoting healthy behavior and ideal weight. In Proceedings of the SIGCHI Conference on Human Factors in Computing Systems (pp. 423-432). ACM.

Räisänen, T., Lehto, T., \& Oinas-Kukkonen, H. (2010). Practical findings from applying the PSD model for evaluating software design specifications. In Persuasive Technology (pp. 185-192). Springer Berlin Heidelberg.

Ritterband, L. M., \& Tate, D. F. (2009). The science of internet interventions.

Ritterband, L. M., Thorndike, F. P., Gonder-Frederick, L. A., Magee, J. C., Bailey, E. T., Saylor, D. K., \& Morin, C. M. (2009). Efficacy of an Internet-based behavioral intervention for adults with insomnia. Archives of General Psychiatry, 66(7), 692.

Seligman, L. D., \& Ollendick, T. H. (2011). Cognitive behavioral therapy for anxiety disorders in youth. Child and adolescent psychiatric clinics of North America, 20(2), 217.

Sivertsen, B., Omvik, S., Pallesen, S., Bjorvatn, B., Havik, O. E., Kvale, G., ... \& Nordhus, I. H. (2006). Cognitive behavioral therapy vs zopiclone for treatment of chronic primary insomnia in older adults. JAMA: the journal of the American Medical Association, 295(24), 2851-2858.

Stibe, A., Oinas-Kukkonen, H., \& Lehto, T. (2013, January). Exploring Social Influence on Customer Engagement: A Pilot Study on the Effects of Social Learning, Social Comparison, and Normative Influence. In System Sciences (HICSS), 2013 46th Hawaii International Conference on (pp. 2735-2744). IEEE.

Stibe, A., \& Oinas-Kukkonen, H. (2012, October). Exploring the Effects of Social Influence on User Behavior Targeted to Feedback Sharing. In B. White (Ed.), Proceedings of the IADIS WWW/Internet Conference (ICWI), Madrid, Spain. 
Straus, A., \& Corbin, J. (1998). Basics of qualitative research: Techniques and procedures for developing grounded theory. $2 n d E d$.

Ström, L., Pettersson, R., \& Andersson, G. (2004). Internet-based treatment for insomnia: a controlled evaluation. Journal of consulting and clinical psychology, 72(1), 113.Thorpe, G. L., Hecker, J. E., Cavallaro, L. A., and Kulberg, G. E. (1987). Insight Versus Rehearsal in Cognitive-Behavior Therapy: A Crossover Study with Sixteen Phobics. Behavioral psychotherapy, 15(4), 319-336.

Thom, D. H., \& Campbell, B. (1997). Patient-physician trust: an exploratory study. Journal of Family Practice, 44(2), 169-177.

Tørning, K., \& Oinas-Kukkonen, H. (2009, April). Persuasive system design: state of the art and future directions. In Proceedings of the 4th International Conference on Persuasive Technology (p. 30). ACM.

Vincent, N., \& Lewycky, S. (2009). Logging on for better sleep: RCT of the effectiveness of online treatment for insomnia. Sleep, 32(6), 807-815.

van Straten, A., \& Cuijpers, P. (2009). Self-help therapy for insomnia: a meta-analysis. Sleep Medicine Reviews, 13(1), 61-71.

Walsh, J. K. (2004). Clinical and socioeconomic correlates of insomnia. Journal of Clinical psychiatry, 65(8), 13-19.

Webb, T. L., Joseph, J., Yardley, L., \& Michie, S. (2010). Using the internet to promote health behavior change: a systematic review and meta-analysis of the impact of theoretical basis, use of behavior change techniques, and mode of delivery on efficacy. Journal of medical Internet research, 12(1).

Webster, J. and Ahuja, J.S., (2006). Enhancing the design of web navigation systems: The influence of user disorientation on engagement and performance. MIS Quarterly 30, 3, 661-678.

Wiafe, I., Nakata, K., Moran, S., Gulliver, S., (2011). Considering user attitude and behavior in persuasive systems design: The 3D-RAB MODEL. ECIS 2011 Proceedings. Paper 186. Available at: http://aisel.aisnet.org/ecis2011/186 (Last accessed: Oct 29, 2011)

Ybarra, M. L., \& Eaton, W. W. (2005). Internet-based mental health interventions. Mental health services research, 7(2), 75-87.

Yetim, F. (2011). A set of critical heuristics for value sensitive designers and users of persuasive systems. 


\section{AUTHORS' BIO}

Sitwat Usman Langrial, Ph. D in Health Information Systems, is currently working as the Assistant Dean for Academic \& Research Affairs at Sur University College, Sultanate of Oman. He has authored over 20 peer reviewed scientific articles and book chapters. His primary research interests include Behavior Change Interventions, Persuasive Information Systems, Acceptance \& Commitment Therapy, eHealth and Information Systems for Mental Health Care.

Harri Oinas-Kukkonen, $\mathrm{Ph} . \mathrm{D}$ is a professor in Information Systems at the Faculty of Information and Electrical Engineering at Oulu University, Finland. His research interests include Human Computer Interaction, User Behavior, Behavior Change, Persuasive Design and the next generation of the Web. More recently, he has coauthored a book titled, "Humanizing the Web: Change and Social Innovation"(Palgrave MacMillan, 2013).

Päivi Lappalainen, Ph.D. in Clinical Psychology, is currently working as a Post Doctoral Researcher at the Department of Psychology at the University of Jyväskylä, Finland. She is authored over 20 scientific articles and books. Her primary research interests include Acceptance and Commitment Therapy, in particular web and mobile interventions for depression, sleep and general well-being. She also has several years of experience in the field of Higher Education and web-based learning.

Raimo Lappalainen, Ph.D. in Clinical Psychology, professor in Clinical Psychology and Psychotherapy at the Department of Psychology, University of Jyväskylä, Finland. $\mathrm{He}$ is a licensed psychologist and psychotherapist. He has over 25 years of experience of Cognitive Behavioral Therapies (CBT) with expertise especially in the third wave CBT, Acceptance and Commitment Therapy (ACT). He has authored more than 100 scientific articles and books. His current research interests include Acceptance and Commitment Therapy, Web/Mobile-based interventions and brief psychological interventions. 